\title{
Cartografía de un nuevo Modelo de Estados y Transiciones de la Estepa Magallánica Seca en la Patagonia argentina
}

\author{
Cintia Schenkel ${ }^{12,10} ;$ Gabriel E. Oliva $^{1,2} ;$ Paula N. Paredes $^{12,2}$; Gervasio Humano ${ }^{1}$ \\ \& Daniela Ferrante ${ }^{1,2}$ \\ ${ }^{1}$ INTA EEA Santa Cruz. Río Gallegos, Santa Cruz. ${ }^{2}$ Universidad Nacional de la Patagonia Austral (UNPA), Unidad
Académica Río Gallegos. Santa Cruz, Argentina.
}

\begin{abstract}
Resumen. Analizamos 103 censos de vegetación de la Estepa Magallánica Seca, un área de $12000 \mathrm{~km}^{2}$ de estepas graminosas semiáridas en el SE de la Patagonia. Los objetivos del presente trabajo fueron ampliar el relevamiento de vegetación de la región, clasificar las principales comunidades, interpretarlas en función de Modelos de Estados y Transiciones (MEyT), cartografiar su distribución espacial y buscar evidencias de posibles transiciones mediante análisis de contrastes de alambrado. El análisis de conglomerados definió 10 comunidades vegetales, algunas de las cuales no estaban contempladas en el MEyT previo, por lo que fue necesario generar un nuevo MEyT. Este modelo incluye transiciones ya descriptas previamente, en las que la erosión expone horizontes $B_{t}$ y genera condiciones favorables a Estepas Subarbustivas, pero además, otras en las cuales se acumulan sedimentos que favorecen a Pappostipa chrysophylla, una gramínea psamófila invasora. Tres estados que se diferenciaban en el modelo anterior por cambios reversibles de cobertura de pastos cortos fueron combinados para reflejar solamente transiciones irreversibles. Para la cartografía se trazaron polígonos alrededor de cada censo sobre imágenes satelitales LANDSAT, se combinaron de acuerdo con el análisis de agrupamiento, se obtuvieron firmas espectrales, se clasificaron y se agruparon las clases del mapa en cinco estados. La precisión del mapa fue mayor al 61\%. El 39\% del área correspondió a Coironales en buena condición de conservación, dominantes al sur. Le siguen en importancia las Estepas Subarbustivas con P. chrysophylla (18\%) y las Estepas Subarbustivas (15\%), ambas degradadas. Los contrastes de alambrados evidenciaron transiciones que habían sido hipotetizadas en el modelo, como las que llevaron a Estepas Subarbustivas degradadas asociadas probablemente a un pastoreo de invernada intenso previo. El mapa y el MEyT que se presentan en este trabajo permiten interpretar mejor la dinámica de la Estepa Magallánica Seca, una de las áreas ecológicas más diversas y productivas de la Patagonia, que muestra extensas áreas degradadas. Estos pastizales deberían ser protegidos en el futuro, ya que no existen prácticamente áreas de conservación. En este sentido, toda la región debería ser conservada por medio de un manejo de cargas ganaderas moderadas y descansos que aseguren el mantenimiento de la biodiversidad, productividad y servicios ecosistémicos.
\end{abstract}

[Palabras clave: pastizales naturales, ganadería ovina, arbustización, degradación, desertificación, biodiversidad]

\begin{abstract}
A State and Transition Map for the Dry Magellan Steppe, Patagonia, Argentina. We analyzed 103 vegetation relevés in the Dry Magellan Steppe, a $12000 \mathrm{~km}^{2}$ semiarid biozone (170-270 mm of annual rainfall) dominated by grass steppes in the SE of Patagonia. The objective was to map rangeland states within the State and Transition Model (STM). Cluster analysis showed 10 communities, some of them not included in previous STM models of the region, so that a new model was designed. In addition to already described transitions such as those driven by erosion that exposes argillic soil horizons covered by dwarf Shrub Steppes, the new model includes transitions driven by eroded soil accumulation that benefit Pappostipa chrysophylla, an invasive psammophyle grass species. Three states previously differentiated by short grass cover were combined in order to reflect only irreversible transitions. Maps were obtained by drawing polygons around each relevé, grouping them in accordance to the classes defined by cluster analysis and extracting spectral firms of these areas in a Landsat 8 image. These classes were grouped into five states. We estimated $61 \%$ precision of the map. Tussock grasslands in good conservation state occupied $39 \%$ and were dominant in the south of the area. Degraded dwarf shrub steppes with $P$. chrysophylla (18\%) and dwarf shrub steppes (15\%) were next in importance. Fence contrasts in the map show some of the hypothesized transitions, such as those that lead to dwarf shrub or dwarf shrubs with $P$. chrysophylla in highly grazed wintering areas in the north. The map and new STM will help to interpret the dynamics of the Magellan Steppe, one of the most diverse and productive biozones of Patagonia that shows clear evidence of past degradation. Some of these rangelands should probably be protected in the future, as conservation areas are almost nonexistent. In this sense, all of the region should be conserved in productive units by managing grazing with moderate stocking rates and rests in order to ensure conservation of biodiversity, productivity and other ecosystem services.
\end{abstract}

[Keywords: rangelands, sheep, grazing, shrub increase, degradation, desertification, biodiversity] 


\section{INTRODUCCIÓN}

La Provincia Fitogeográfica Patagónica es extensa y heterogénea (Cabrera 1971). La vegetación posee allí un gran número de endemismos y especies con adaptaciones a ambientes áridos (Soriano et al. 1995). La porción más austral de la región está dominada por estepas graminosas de Festuca gracillima o coirón fueguino. En la clasificación fitogeográfica de Cabrera (1971), la región fue incluida en el Distrito Subandino, pero la especie dominante de este distrito, Festuca pallescens, está presente sólo en áreas de humedales. Estas diferencias florísticas con el resto de la región subandina y la similitud de la vegetación a ambos lados del Estrecho de Magallanes llevó a Anchorena (1978) a definir un área ecológica común: la Estepa Magallánica. El área fue analizada en la Transecta Botánica Austral (Faggi 1983, 1985;
Roig et al. 1985), y allí se diferenciaron las variantes secas (Nardophyllo-Festucetalia) y húmedas (Gamochaeto-Festucetalia) para la Estepa Magallánica. Borrelli et al. (1987) retomaron esta diferenciación en Estepa Magallánica variante este y oeste, ambas graminosas, pero la segunda con mayor cobertura. León et al. (1998) definieron al área como Distrito Magallánico y, al igual que los autores anteriores, reconocieron una variante húmeda denominada Estepa Graminosa Húmeda y una seca que llamaron Estepa Graminosa Xérica. Oliva et al. (2001) consideraron a las estepas graminosas del sur de Santa Cruz como dos áreas ecológicas distintas: la Estepa Magallánica Húmeda y la Estepa Magallánica Seca, utilizando el mismo criterio de humedad/xericidad. Esta clasificación fue utilizada por Bran et al. (2005) en el mapa de Áreas Ecológicas de la Patagonia (Figura 1).

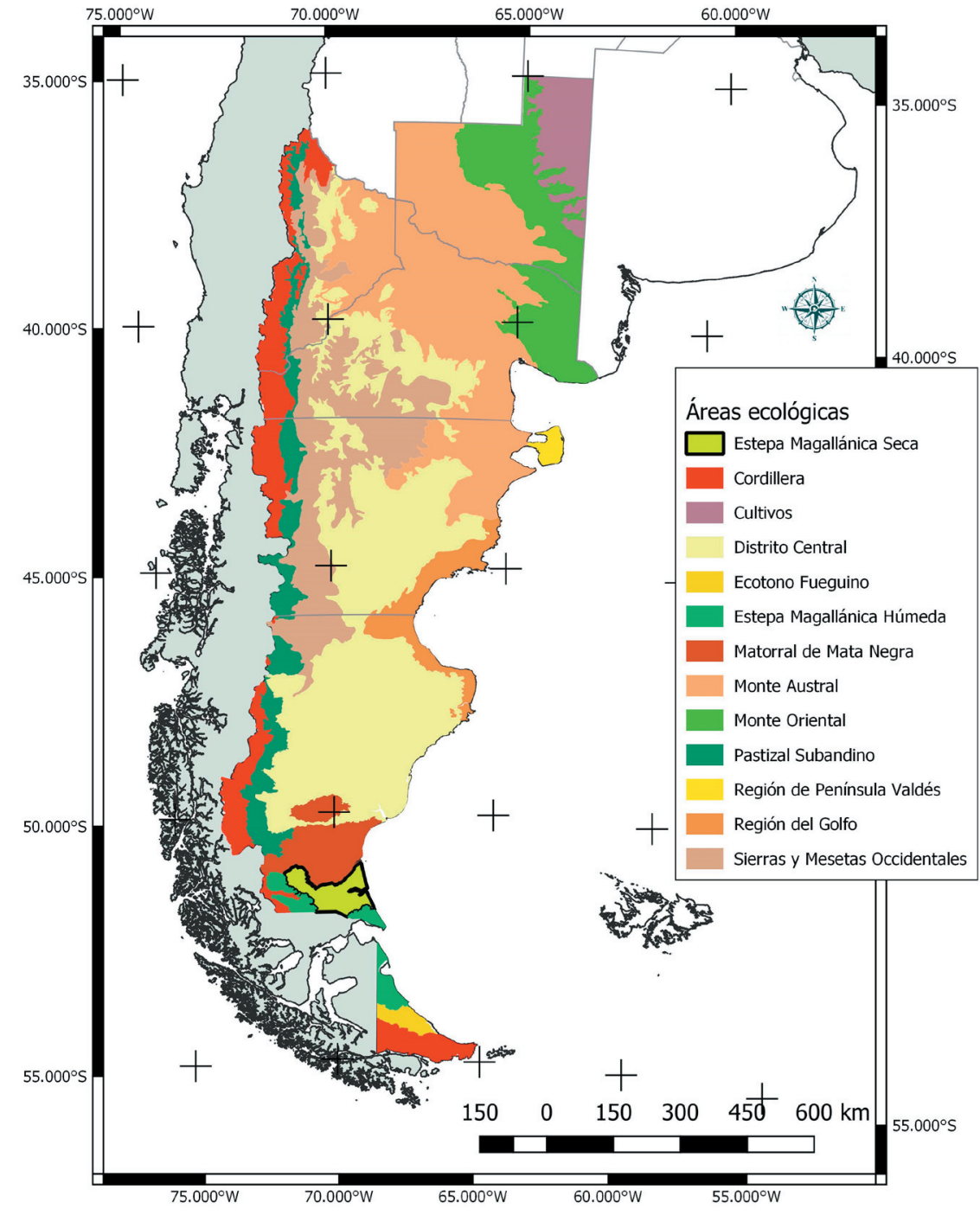

Figura 1. Áreas ecológicas de la Patagonia (Bran et al. 2005). El límite de la Estepa Magallánica Seca se presenta en línea gruesa.

Figure 1. Map of ecological areas of Patagonia (Bran et al. 2005). Limits of the Dry Magellan Steppe Area in bold line. 
La Estepa Magallánica, como la mayoría de los pastizales naturales de la Patagonia, ha sido sometida a más de un siglo de pastoreo y presenta diversos grados de degradación. Los estudios iniciales de pastizales en la región se realizaron en el marco de la evaluación de 'condición' (Dyksterhuis 1958), y se caracterizaron los sitios de Terraza del Río Gallegos (Borrelli et al. 1984) y Santacrucense (Borrelli et al. 1988). A partir de la publicación del esquema teórico de Modelos de Estados y Transiciones (MEyT) (Westoby et al. 1989) se reconoció que los pastizales exhiben múltiples estados constituidos por comunidades vegetales relativamente estables que pueden individualizarse en base a la fisonomía de la vegetación, la productividad y la diversidad. El cambio entre estados se denomina transición; las transiciones pueden ser reversibles o irreversibles, en el caso de que el disturbio supere un determinado umbral (Friedel 1991; Laycock 1991). En base a los estudios de condición publicados en la década del ochenta y a nuevos censos, Oliva y Borrelli (1993) presentaron un MEyT para el área (Figura 2), que propone un estado de Pastizal de alta cobertura cerrado de una gramínea de mediano porte (Festuca gracillima), que con una presión moderada de pastoreo generaría pastizales abiertos de la misma especie. En el caso de que el pastoreo continuara, la cobertura de leñosas aumentaría y el pastizal cambiaría de fisonomía a Estepa Subarbustiva de Nardophyllum bryoides, una especie de Asteraceae subarbustiva presente en estos pastizales. En sectores de intensos procesos de erosión y deposición de material se generaría la transición final a una Estepa Subarbustiva de Nassauvia ulicina y Pappostipa chrysophylla. La primera corresponde a un subarbusto de la familia Asteraceae, y la segunda, también denominada 'coirón amargo', es una gramínea mediana psamófila. Todas estas transiciones serían irreversibles. Sin embargo, el modelo plantea que, en el caso de que la presión de pastoreo disminuya, se producirían transiciones reversibles por aumento de pastos cortos.

La distribución geográfica de los estados postulados en el primer MEyT no fue analizada, ya que la confección de un mapa de este tipo requiere un número elevado de censos florísticos representativos y una capacidad de análisis de imágenes que no estaban disponibles en ese momento. La cartografía a escala predial de los estados descriptos es necesaria para determinar pautas de manejo ganadero, posibilidades de recuperación de áreas degradadas y el valor de conservación y diversidad de la comunidad vegetal (Bestelmeyer et al. 2003). Los objetivos del presente trabajo fueron ampliar el relevamiento de vegetación a toda la Estepa Magallánica Seca, clasificar las principales comunidades, interpretarlas en función de MEyT, cartografiar su distribución espacial y buscar evidencias de posibles transiciones mediante el análisis de contrastes de alambrado.

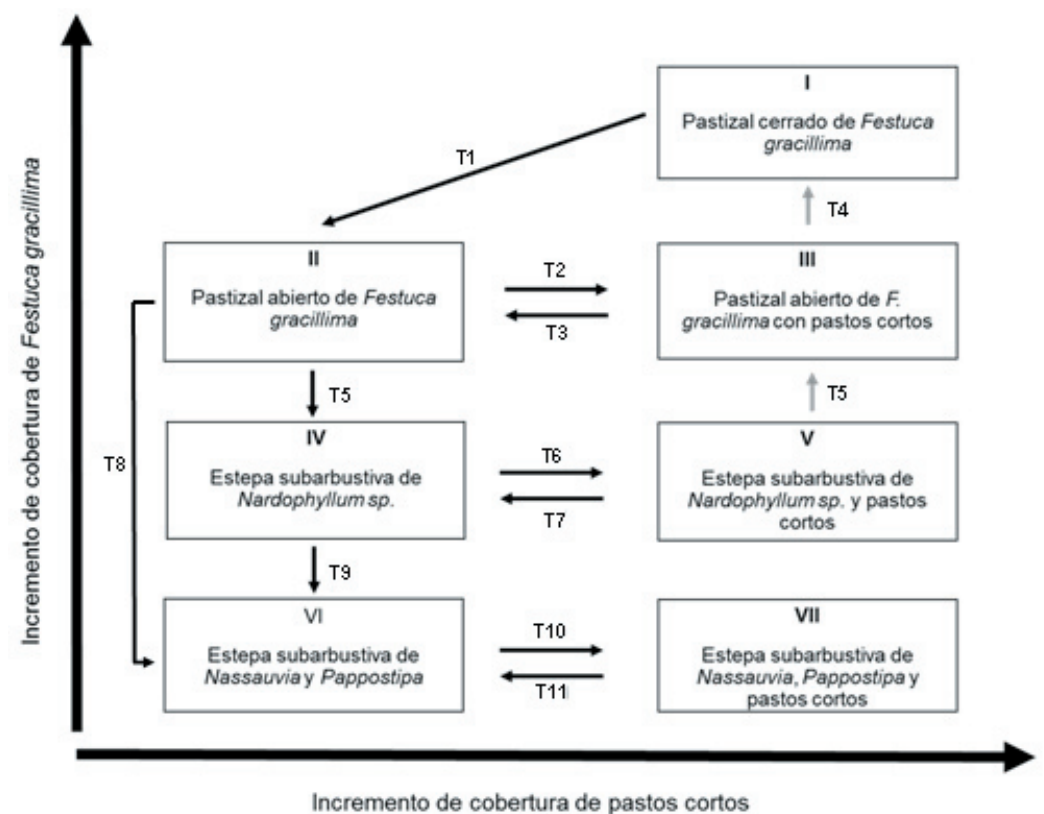

Incremento de cobertura de pastos cortos
Figura 2. Esquema del Modelo de Estados y Transiciones para la Estepa Magallánica Seca de Oliva y Borrelli (1993).

Figure 2. Original State and Transition Model for the Dry Magellan Steppe redrawn from Oliva and Borrelli (1993). 


\section{Materiales y Métodos}

La Estepa Magallánica Seca ocupa 12000 km² en el extremo SE de la Región Patagónica, entre los $51^{\circ}$ y $52^{\circ}$ de latitud S (Bran et al. 2005) (Figura 1). En este estudio se utilizó la delimitación del área incluida en la cartografía de (Oliva et al. 2001). La precipitación media anual varía en la región entre 170 y $270 \mathrm{~mm}$ (De Fina et al. 1968) y presenta una leve concentración estival, con un $90 \%$ en eventos de lluvia pequeños, menores a $5 \mathrm{~mm}$ (Ferrante et al. 2004). La temperatura media anual es de $7.6{ }^{\circ} \mathrm{C}$. Los vientos son persistentes, de dirección sudoeste y con una velocidad media de 15 a $22 \mathrm{~km} / \mathrm{h}$, con máximas entre septiembre y enero. Burgos (1985) estima para el área una evaporación potencial de $550 \mathrm{~mm}$, con un déficit hídrico de $310 \mathrm{~mm}$.

Desde el punto de vista geológico, el área se desarrolló sobre depósitos sedimentarios mesozoicos y cenozoicos (Ramos 1999). En el Plio-pleistoceno se generó un campo volcánico basáltico alcalino y grandes mantos de rodados patagónicos. Luego, este paisaje fue disectado por valles con depósitos glaciarios y fluvioglaciarios. El paisaje actual es plano o levemente ondulado, dominado por terrazas fluvio-glaciales y mesetas de distintos niveles entre los ríos Gallegos y Chico. Hacia el suroeste existen coladas basálticas y relieves fluviales. Las pendientes leves favorecen la formación de grandes bajos internos que se alimentan mediante una red de pequeños cañadones. Localmente se desarrollan lagunas temporarias asociadas a cubetas de deflación (Mazzoni 2001). La vegetación corresponde fisonómicamente a una estepa graminosa con cobertura vegetal que oscila entre el 50-70\%, dominada por F. gracillima. El uso ganadero del área comenzó en 1886 con la introducción de ovinos (Barbería 1995). Las existencias aumentaron rápidamente y alcanzaron un número estable a principios del siglo XX para luego disminuir lentamente.

\section{Análisis de la vegetación}

Se realizaron 85 censos de vegetación utilizando la metodología Braun Blanquet (1932), a los cuales se adicionaron 18 monitores MARAS (Oliva et al. 2019), totalizando 103 censos (Material Suplementario 1). El muestreo se realizó sobre las estepas graminosas, excluyendo mallines y arbustales. Las especies fueron clasificadas en grupos funcionales: coirones (gramíneas medianas), subarbustos (leñosas enanas), pastos cortos forrajeros y pastos cortos no forrajeros. Se realizó un análisis de conglomerados (AC) a partir de una matriz de distancia BraunBlanquet, utilizando el método promedio de InfoStat (Di Rienzo et al. 2011). Como variables se consideraron los grupos funcionales mencionados y las especies que participan en la definición de estados en el modelo de Oliva y Borrelli (1993): coirones (F. gracillima y $P$. chrysophylla) y subarbustos (N. bryoides y N. ulicina). Se definió una distancia de BraunBlanquet de 0.53 , dado que generó 10 grupos de censos en el dendrograma del análisis de conglomerados (Figura 3), un número de agrupamientos que consideramos adecuado para la cartografía a la escala utilizada. Un total de 12 censos atípicos quedaron sin agrupar.

La cartografía del MEyT se realizó a partir de la selección del área de la Estepa Magallánica Seca en un mosaico satelital de imágenes Landsat 8 (path 228, 229 y 230 y row 096) de cinco bandas. Se enmascararon y excluyeron áreas de valles, marismas, arbustales costeros y la zona urbana de Río Gallegos. Se trazaron polígonos sobre áreas de interés (AOI) de 4-5 píxeles homogéneos asociados a cada censo y se obtuvieron firmas espectrales combinando los AOI de los censos pertenecientes a los 10 grupos definidos por el análisis de conglomerados. Además, se definieron AOI sobre clases especiales, misceláneas, observadas en la imagen (i.e., sombras, nubes, basalto, marismas costeras, lagunas, arbustales de Mulguraea tridens, caminos y pasturas implantadas). A partir de estas firmas espectrales (10 categorías y 1 de áreas misceláneas) se realizó una clasificación supervisada utilizando el método del paralelepípedo y la mínima distancia. Se combinaron las clases de la clasificación supervisada que por su composición florística pertenecían al mismo estado (Figura 3), de modo que en este mapa, las 11 categorías iniciales quedaron reducidas a 6, que representan a cinco estados del MEyT: Coironales, Coironales Subarbustivos, Coironales con P. chrysophylla, Estepas Subarbustivas, Estepas Subarbustivas con $P$. chrysophylla y una clase de cobertura del suelo miscelánea. El mapa final fue homogeneizado mediante dos filtros de paso bajo de 3x3 y de $5 x 5$ y se presentó a una escala 1:250000. Todos los análisis fueron realizados mediante el módulo Supervised-classification de ERDAS Imagine 9.1. 
El mapa fue analizado mediante el cálculo de precisión total, de generación y de uso (Story and Congalton 1986). En la diagonal de esta matriz se consignó el número de puntos de verificación en los cuales la clasificación del mapa coincide con la clasificación de censos en base al análisis de conglomerados. Para la validación y el cálculo de precisión se utilizaron todos los censos que entraron en la construcción del mapa.

Para el análisis de las transiciones se recurrió a la búsqueda de 'contrastes de alambrados', que consisten en rasgos geométricos a lo largo de divisiones catastrales en la cartografía. En un mapa de estados, estos contrastes muestran comunidades que, a pesar de estar en sitios similares en cuanto a clima y suelo, habrían pasado por transiciones (Tabla 2) incluidas en el MEyT propuesto en el presente trabajo y que derivan en cambios en su composición (Figura 4). Esta metodología fue muy usada en los EE.UU. (Cook and Kothmann 1965), aunque, como señala Hongslo (2015), tiene limitaciones, ya que no es posible conocer el conjunto de diferencias que el manejo en

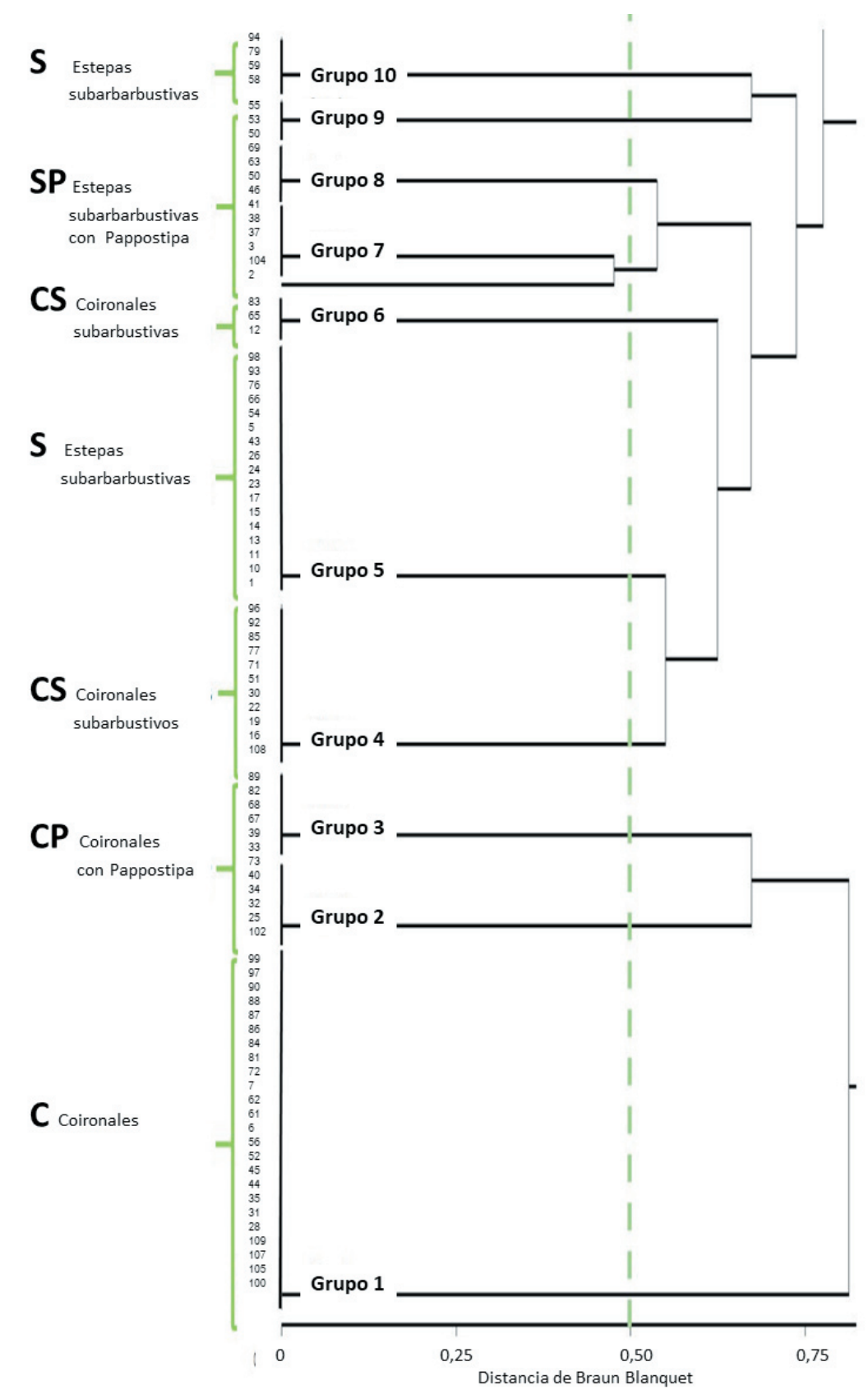

Figura 3. Análisis de conglomerados de los censos de la Estepa Magallánica Seca.

Figure 3. Cluster analysis of vegetation relevés of the Dry Magellan Steppe. 
áreas adyacentes tuvieron en su historia, y frecuentemente se emplearon para justificar 'narrativas de la degradación' particulares.

\section{Resultados}

La lista florística total incluyó 109 taxones, $92 \%$ de los cuales fueron perennes y $7 \%$ anuales. El 83\% son endémicos, el $9 \%$ nativos no endémicos y los restantes fueron adventicios o introducidos (Zuloaga et al. 2009). Los 10 grupos de censos obtenidos en el análisis de conglomerados (Figura 3), no corresponden completamente a los estados descriptos por Oliva y Borrelli (1993) (Tabla 1). Cuatro de estos grupos (Figura 3), que abarcaron casi un tercio de los censos realizados, no se pueden asimilar a ninguno de los estados descriptos en el MEyT de Oliva y Borrelli (1993). Entre ellos, los grupos 2, 3 (ambos Coironales) y 7 (Estepa Subarbustiva) son comunidades en las cuales $P$. chrysophylla supera el 5\%. Las Estepas Subarbustivas de N. ulicina sin P. chrysophylla, grupo 9, tampoco se corresponden con los estados planteados por Oliva y Borrelli (1993). A su vez, algunos grupos del análisis de conglomerados reúnen a más de un estado del antiguo MEyT, como en el caso del grupo 1, que incluye los estados I, II y III, dominados por F. gracillima. El grupo 5 se asocia a las Estepas Subarbustivas e incluye los estados IV y V. El grupo 8, por su lado, corresponde a Estepas Subarbustivas de N. ulicina de estados VI y VII. La falta de correspondencia del modelo teórico con este análisis ampliado de censos de vegetación llevó a plantear un modelo alternativo (Figura 4) en el que se consideraron nuevos estados y se fusionaron otros existentes. El modelo se completa con un catálogo de estados (Figura 5) y un catálogo de transiciones (Tabla 2). En el Material Suplementario 2 se presenta un conjunto de censos representativos de los nuevos estados; el Material Suplementario 3 incluye un resumen de la cobertura de las principales especies que fueron consideradas como crecientes y decrecientes en Oliva et al. (1998), y en el Material Suplementario 4, un catálogo fotográfico de estados.

E1 mapa (Figura 6) de la Estepa Magallánica Seca mostró una dominancia de Coironales, con un 39\% del área total (Tabla 3). En importancia siguen las Estepas Subarbustivas con $P$. chrysophylla y luego las Estepas Subarbustivas. Las áreas que no correspondieron claramente a comunidades vegetales y se clasificaron como misceláneas representaron una baja proporción de la imagen (14\%). Los estimadores de precisión para la cartografía de los estados (Tabla 4) mostraron que la precisión total del mapa fue de $61 \%$. La precisión de la generación fue mayor para los Coironales y los Coironales

Tabla 1. Grupos definidos por el análisis de conglomerados (Figura 3), cantidad de censos que abarca el grupo, rango de coberturas de Festuca, P. chrysophylla, N. bryoides, N. ulicina y otros subarbustos, correspondencia del grupo con estados del I a VII definidos por Oliva y Borrelli (1993) (s/c=no hubo correspondencia), y correspondencia del grupo con estados en el presente trabajo (C: Coironal de F. gracillima; Cs: Coironal Subarbustivo de F. gracillima y N. bryoides; Cp: Coironal de F. gracillima y N. bryoides con P. chrysophylla; S: Estepa Subarbustiva de N. bryoides o N. ulicina; Sp: Estepa Subarbustiva de N. bryoides o N. ulicina con P. chrysophylla).

Table 1. Groups defined by cluster analysis of vegetation relevés in Figure 3, number of relevés included in each group, cover range (\%) of F. gracillima, P. chrysophylla, N. bryoides, N. ulicina and other dwarf shrubs, matching of the group with states I through VII defined previously by Oliva and Borrelli (1993) (s/c=no matching), and matching of the group with states defined in this paper (C: Tussock grassland of F. gracillima; Cs: Tussock grassland of F. gracillima with dwarf N. bryoides shrubs; Cp: Tussock grassland of F. gracillima with dwarf N. bryoides shrubs and P. chrysophylla; S: Dwarf shrubland with N. bryoides or N. ulicina; Sp: Dwarf shrubland with N. bryoides or N. ulicina and P. chrysophylla).

\begin{tabular}{|c|c|c|c|c|c|c|c|c|}
\hline \multirow[b]{2}{*}{$\begin{array}{c}\text { Grupo } \\
\text { análisis de } \\
\text { conglomerados }\end{array}$} & \multirow[b]{2}{*}{$\begin{array}{c}\text { № de } \\
\text { censos } \\
\text { incluidos }\end{array}$} & \multicolumn{5}{|c|}{ Rango de cobertura } & \multirow[b]{2}{*}{$\begin{array}{c}\text { Estado } \\
\text { Oliva } \\
1993\end{array}$} & \multirow[b]{2}{*}{$\begin{array}{c}\text { Estado } \\
\text { propuestos } \\
\text { en este } \\
\text { trabajo }\end{array}$} \\
\hline & & $\begin{array}{c}F . \\
\text { gracillima } \\
(\%)\end{array}$ & $\begin{array}{c}P . \\
\text { chrysophylla } \\
(\%)\end{array}$ & $\begin{array}{l}N . \\
\text { bryoides } \\
(\%)\end{array}$ & $\begin{array}{c}\text { N. } \\
\text { ulicina } \\
(\%)\end{array}$ & $\begin{array}{c}\text { Otros } \\
\text { subarbustos } \\
(\%) \\
\end{array}$ & & \\
\hline 1 & 24 & $15-40$ & $0-2$ & $0-5$ & 0 & $0-15$ & I II III & C \\
\hline 2 & 6 & $0-15$ & 5 & 0 & 0 & $0-10$ & $\mathrm{~s} / \mathrm{c}$ & $\mathrm{Cp}$ \\
\hline 3 & 12 & $15-30$ & $3-25$ & $0-10$ & 0 & $0-10$ & $\mathrm{~s} / \mathrm{c}$ & $\mathrm{Cp}$ \\
\hline 4 & 11 & $15-30$ & $0-2$ & $10-25$ & 0 & $15-30$ & II & Cs \\
\hline 5 & 16 & $0-15$ & $0-2$ & $10-30$ & 0 & $15-30$ & IV V & $S$ \\
\hline 6 & 3 & $20-25$ & 0 & 10 & 0 & $10-15$ & II & Cs \\
\hline 7 & 6 & $0-10$ & $5-20$ & $10-20$ & 0 & $15-35$ & $\mathrm{~s} / \mathrm{c}$ & Sp \\
\hline 8 & 4 & 0 & $5-15$ & 0 & $10-20$ & $20-30$ & VI VII & Sp \\
\hline 9 & 3 & 0 & 0 & $0-5$ & $20-25$ & $25-35$ & $\mathrm{~s} / \mathrm{c}$ & S \\
\hline 10 & 4 & 0-15 & 0 & $0-5$ & 0 & $15-25$ & $\mathrm{~V}$ & $S$ \\
\hline
\end{tabular}


Tabla 2. Catálogo de transiciones asociadas al Modelo de Estados y Transiciones de la Estepa Magallánica Seca.

Table 2. Transition catalog for the State and Transition Model of the Dry Magellan Steppe.

\begin{abstract}
Transición $1 \quad$ El pastoreo de altas cargas reduce la cobertura de F. gracillima y produce desagregación de los montículos con liberación de suelo y posterior erosión. La pérdida de cobertura de especies graminosas favorece a los subarbustos de $N$. bryoides por menor competencia por agua y nutrientes
\end{abstract}

Transición 2 y 3 Coironal de F. gracillima (C) y Coironal Subarbustivo de F. gracillima y N. bryoides (Cs) se cubren con acumulaciones de arena de espesor variable por sobrepastoreo, erosión y movilización desde áreas cercanas. Sobre este material eólico se instalan propágulos de coirón amargo $(P$. chrysophylla), una especie psamófila, dando lugar a Coironal de F. gracillima y N. bryoides con $P$. chrysophylla (Cp). La proporción de P. chrysophylla es variable hasta llegar a una dominancia total en áreas medanosas. Una vez instalada P. chrysophylla, y aun si se interrumpe el ingreso de material arenoso, es muy difícil que $F$. gracillima la desplace competitivamente

Transición 4

Las gramíneas altas remanentes en el Coironal Subarbustivo de F. gracillima y N. bryoides (Cs) se pierden por pastoreo intenso, los montículos se desestructuran y disminuyen los elementos rugosos. Aumenta la intensidad del viento sobre la superficie de suelo y la pérdida del horizonte superficial expone los horizontes $B_{t}$. Esta superficie no ofrece sitios seguros para los propágulos y resulta en un impedimento físico para las raíces de las gramíneas. La transición 4 tendría dos variantes, por deflación dominante sobre suelos con horizontes argílicos se originarían las Estepas Subarbustivas dominadas por N. bryoides, mientras que una combinación de erosión hídrica y eólica con altas cargas y aporte de nutrientes por bosteo, comunes en pendientes con orientación norte, daría origen a una variante con $N$. ulicina, asociada a suelos $\mathrm{B}$ cámbicos $\left(\mathrm{B}_{\mathrm{w}}\right)$ que tienen una mayor proporción de limos y tienden a compactarse. Esto podría favorecer los sistemas radiculares superficiales de N. ulicina

Transición 5 Sobre los horizontes $\mathrm{B}_{\mathrm{t}}$ o $\mathrm{B}_{\mathrm{w}}$ de las Estepa Subarbustiva de N. bryoides o N. ulicina(S) se depositan sedimentos arenosos que son colonizados por P. chrysophylla, generando Estepa Subarbustiva de N. bryoides o N. ulicina con Pappostipa (Sp)

Transición 6

El proceso de acumulación de sedimentos eólicos da lugar a una fase de deflación, exponiendo el horizonte subsuperficial donde se instalan subarbustos de N. ulicina

Transición 7

La acumulación de arena sobre las estepas degradadas se intensifica, lo que favorece a las especies psamófilas, dando lugar a la variante de Cp que tiene a P. chrysophylla (coirón amargo) como dominante exclusivo

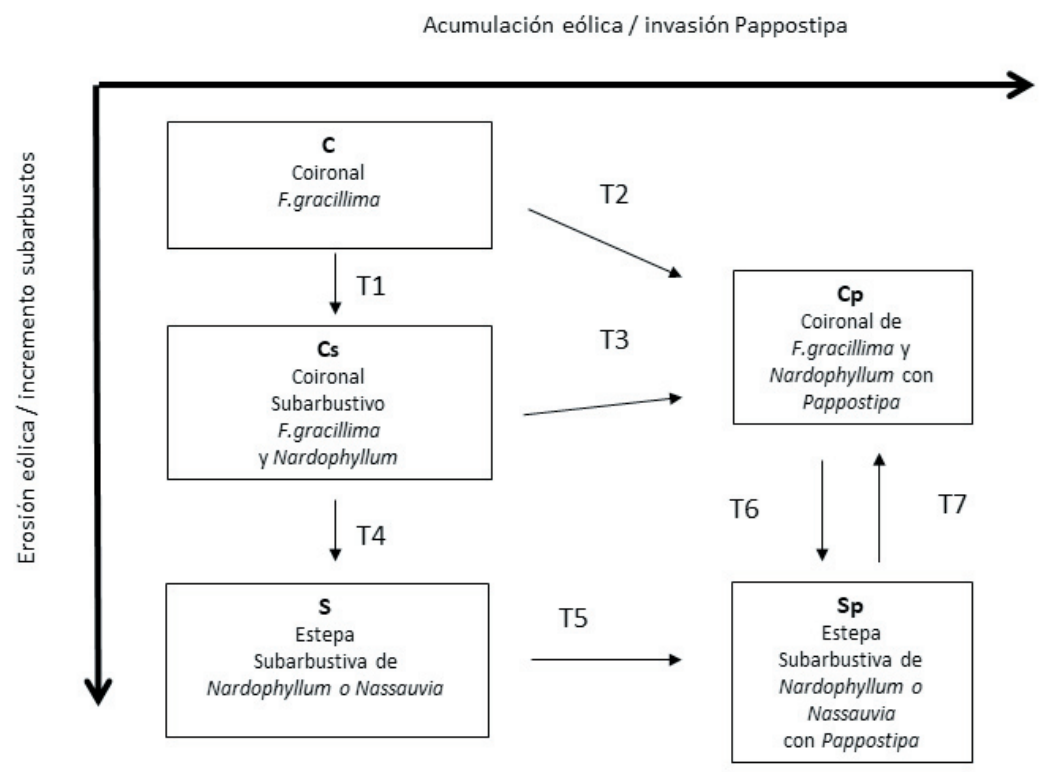

Figura 4. Nuevo Modelo de Estados y Transiciones propuesto para la Estepa Magallánica Seca. Ver descripción de estados en Figura 5 y transiciones (1 a 7) en Tabla 4.

Figure 4. New State and Transition Model for the Dry Magellan Steppe. Description of states in Figure 5 and transitions (1 through 7$)$ in Table 4. 
Tabla 3. Estados definidos en el Modelo de Estados y Transiciones de la Estepa Magallánica Seca, superficie que ocupan en hectáreas y porcentaje.

Table 3. States of the Dry Magellan Steppe, area occupied in hectares and percentage.

\begin{tabular}{|c|c|c|}
\hline \multirow[t]{2}{*}{ Estado } & \multicolumn{2}{|c|}{ Superficie } \\
\hline & (ha) & $(\%)$ \\
\hline Coironal de $F$. gracillima $(\mathrm{C})$ & 465539 & 39 \\
\hline $\begin{array}{l}\text { Coironal Subarbustivo de } \\
\text { F. gracillima y N. bryoides (CS) }\end{array}$ & 93867 & 8 \\
\hline $\begin{array}{l}\text { Coironal de } F \text {. gracillima y } \\
N \text {. bryoides con } P \text {. chrysophylla (Cp) }\end{array}$ & 70813 & 6 \\
\hline $\begin{array}{l}\text { Estepa Subarbustiva de } \\
\text { N. bryoides o N. ulicina (S) }\end{array}$ & 179139 & 15 \\
\hline $\begin{array}{l}\text { Estepa Subarbustiva de } \\
\text { N. bryoides o N. ulicina con } \\
\text { P. chrysophylla (Sp) }\end{array}$ & 219091 & 18 \\
\hline Misceláneas* & 161257 & 14 \\
\hline Total & 1189709 & 100 \\
\hline
\end{tabular}

Subarbustivos, pero baja para los Coironales con $P$. chrysophylla en relación a la total. En cuanto a la precisión del uso del mapa, fue para la mayoría de los estados cartografiados cercana o superior al 70\%, a excepción de las Estepas Subarbustivas con $P$. chrysophylla, que resultaron en una precisión de menos del $30 \%$.

El mapa (Figura 6) muestra que los Coironales (C) se ubican principalmente hacia el sur del río Gallegos y en un sector hacia el norte del estuario del mismo. Los Coironales Subarbustivos (Cs) se disponen en forma de manchones en la matriz de los Coironales. Los Coironales invadidos por $P$. chrysophylla (Cp) ocupan menor superficie, y están generalmente cercanos al valle del río o bordeando cuerpos de agua someros, asociados a médanos, y hacia el NO ocupan extensas áreas de deposición de arenas. Las Estepas Subarbustivas (S) se distribuyen en forma dispersa, pero es notable la formación de tres bloques (i.e., en el centro-norte, en el SE y otro en el NE). Las

Tabla 4. Matriz y cálculos de precisión total, de uso y generación de la cartografía de estados (Story and Congalton 1986). En las filas se encuentra cada estado definido en la clasificación supervisada y en las columnas, los estados diferenciados en el análisis de agrupamiento. Cada celda representa la cantidad de censos que coinciden entre el mapa (clasificación supervisada) y el análisis de agrupamiento (InfoStat). C: Coironal de F. gracillima; Cs: Coironal de F. gracillima con subarbustos de N. bryoides; Cp: Coironal de F. gracillima y N. bryoides invadido por P. chrysophylla; S: Estepa Subarbustiva de N. bryoides o N. ulicina; Sp: Estepa Subarbustiva de N. bryoides o N. ulicina invadida por $P$. chrysophylla.

Table 4. Precision matrix for map generation and use (Story and Congalton 1986) of the state map of the Dry Magellan State. Rows show each state as defined by the supervised classification and columns the states defined by the cluster analysis. Each cell represents the number of relevés that are coincident in the map (supervised classification) and cluster analysis (InfoStat). C: tussock grassland of F. gracillima; Cs: tussock grassland of F. gracillima with dwarf N. bryoides shrubs; Cp: tussock grassland of F. gracillima with dwarf N. bryoides shrubs and P. chrysophylla; S: dwarf shrubland with N. bryoides or N.ulicina; Sp: dwarf shrubland with N. bryoides or N. ulicina and P. chrysophylla.

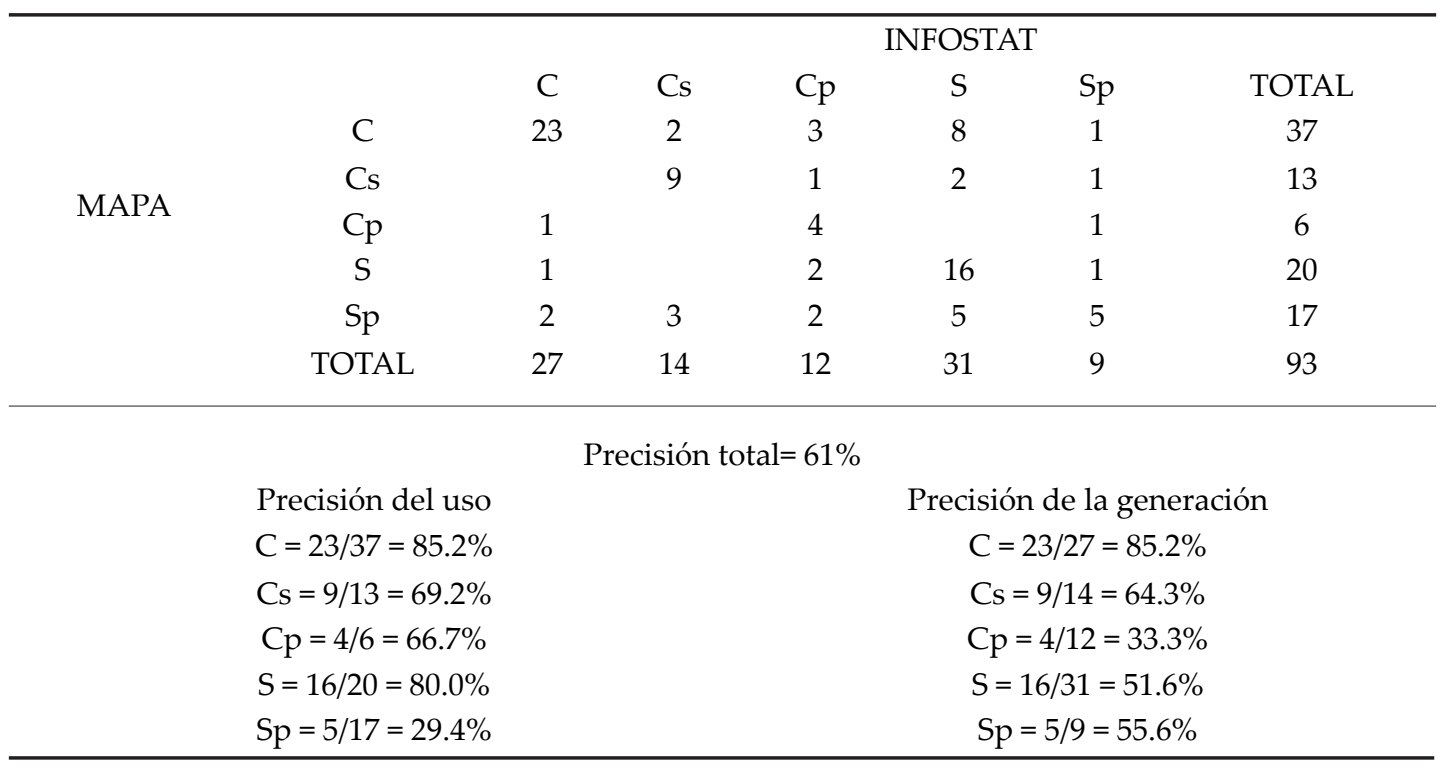




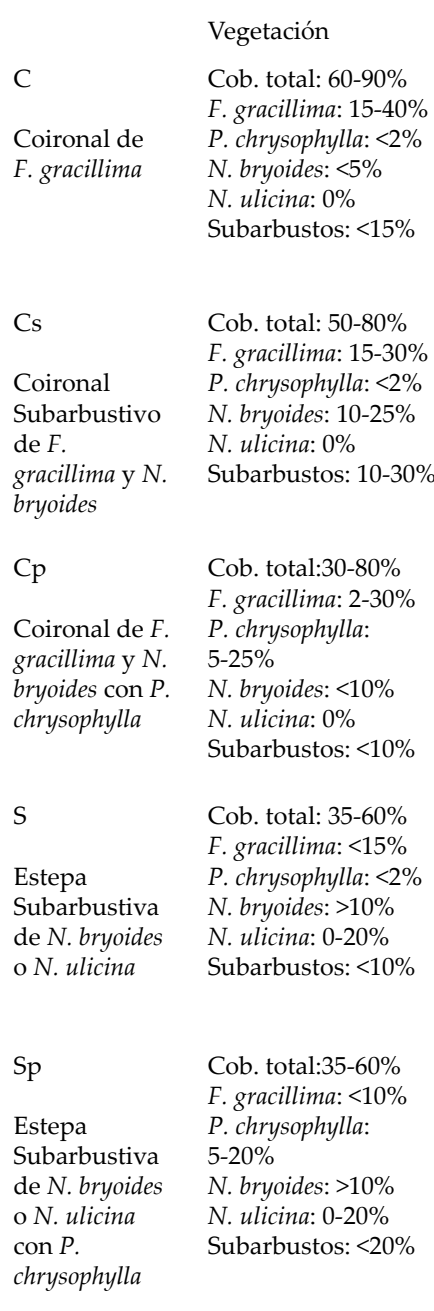

Suelo

Escaso suelo desnudo

Horizonte superficial arenoso y profundo $(>20 \mathrm{~cm})$

Horizonte superficial de 20-16 $\mathrm{cm}$ de espesor discontinuo. Sectores con pavimento erosión (exposición de $\mathrm{B}_{\mathrm{t}}$ ). Plantas en pedestal

Depósitos de arenas en forma de 'islas' (2-5 m) o de manto sobre el horizonte superficial

Horizonte superficial $<16 \mathrm{~cm}$ de espesor. Horizonte $B_{t}$ expuesto genera grandes interparches con pavimento erosión

Depósitos de arenas en forma de 'islas' (2-5 m) o de manto sobre el horizonte superficial o subsuperficial $\left(\mathrm{B}_{\mathrm{t}}\right)$
Perfil
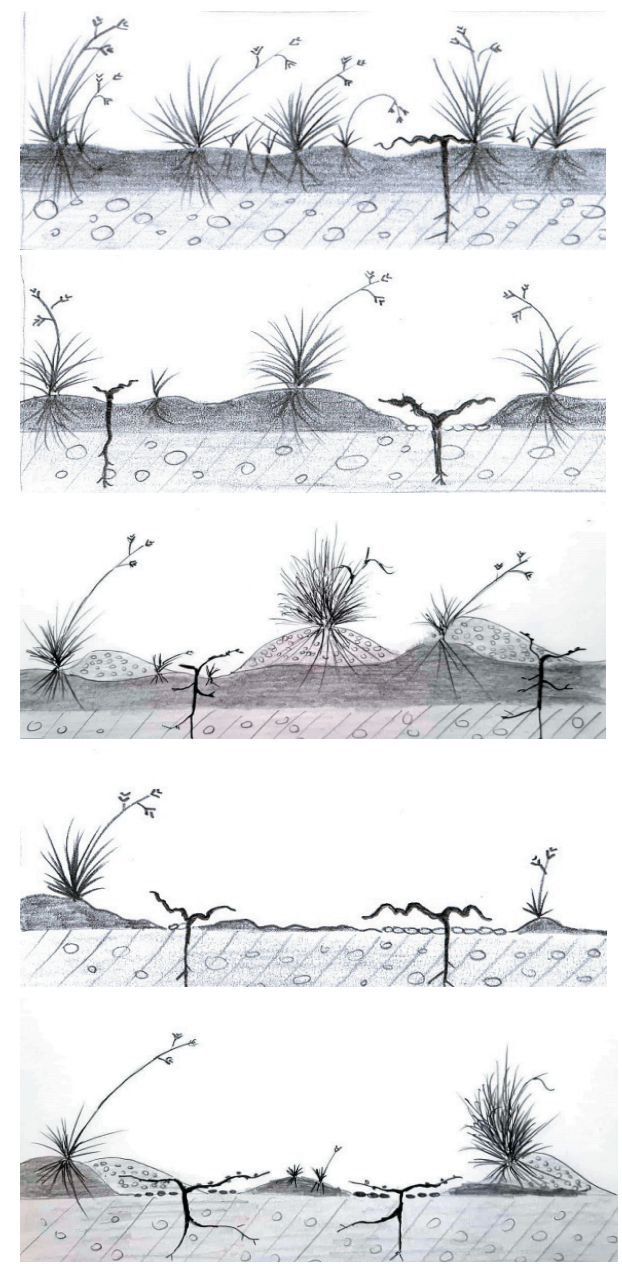

Figura 5. Catálogo de Estados de la Estepa Magallánica Seca. Se muestran los rangos para los valores más frecuentes de cobertura vegetal total y las principales especies.

Figure 5. State catalog of the Dry Magellan Steppe. Most frequent values for vegetation cover and cover of the main species are shown.

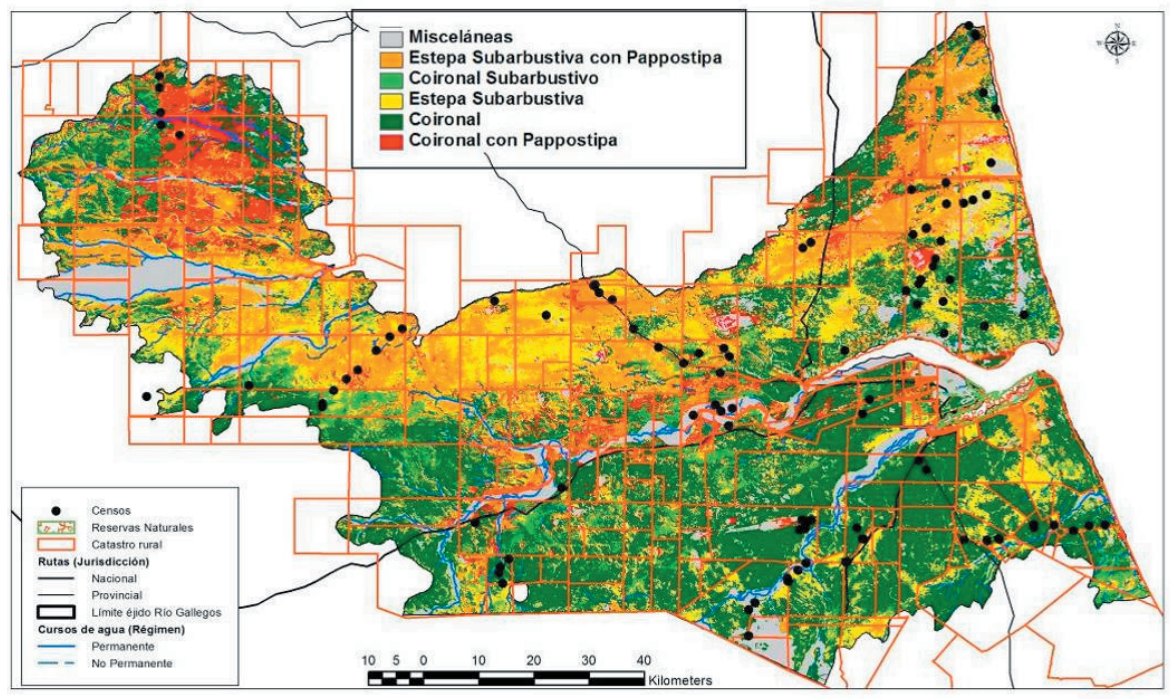

Figura 6. Mapa de estados de la Estepa Magallánica Seca.

Figure 6. Map of states of the Dry Magellan Steppe. 

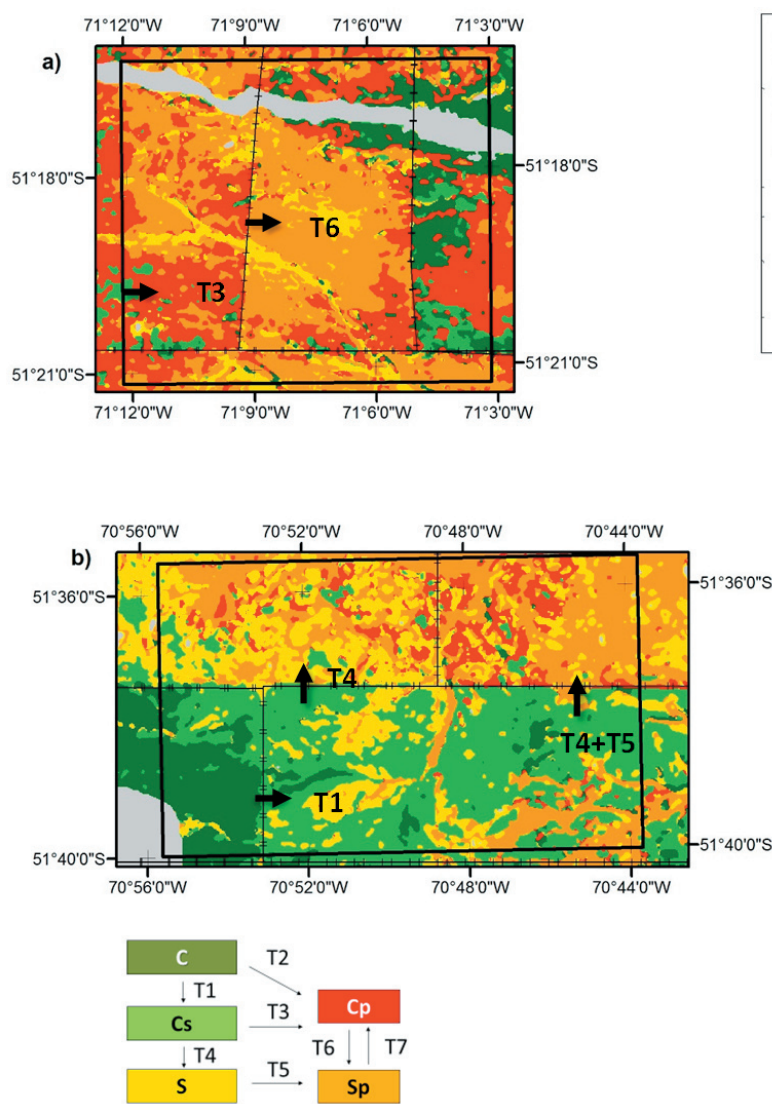
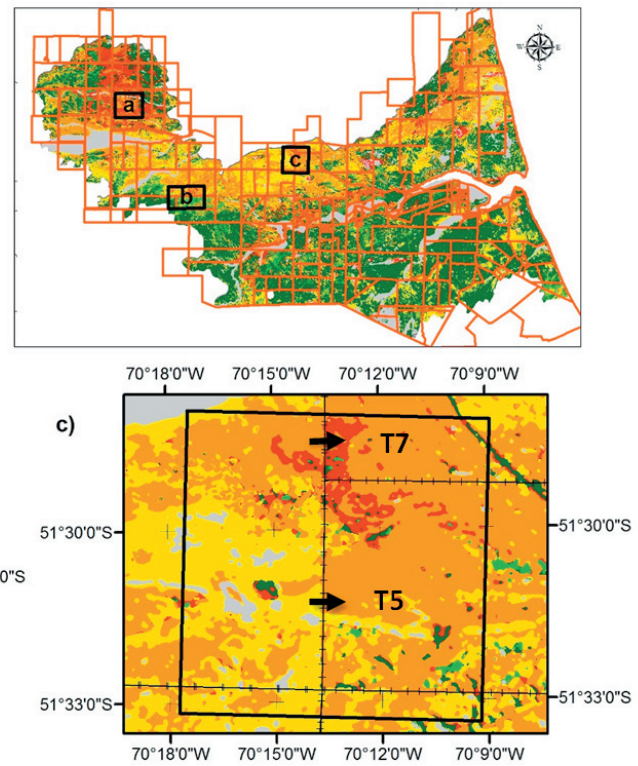

Catastro rural

M Misceláneas

Sp Estepa Subarbustiva con Pappostipa

Cs Coironal Subarbustivo

$\square$ S Estepa Subarbustiva

C Coironal

Cp Coironal con Pappostipa

Figura 7. Contrastes de alambrado que muestran transiciones entre estados.

Figure 7. Fence contrasts that show transitions between states.

Estepas Subarbustivas con P. chrysophylla (Sp) forman una cuña en el centro-norte y limitan con el Matorral de Mata Negra. Se observan contrastes de alambrados, es decir, líneas que siguen divisiones catastrales entre campos que originalmente habrían estado cubiertos por comunidades vegetales similares, pero que sufrieron transiciones por el manejo ganadero (Figura 7).

\section{Discusión}

Los Modelos de Estados y Transiciones son hipótesis sobre la dinámica de la vegetación que se enriquecen a medida que se incorporan elementos para el análisis e interpretación tales como relevamientos florísticos adicionales y mejores instrumentos para la cartografía. Además, los modelos requieren actualizaciones, ya que los marcos conceptuales de MEyT iniciales de Westoby et al. (1989) fueron cambiando (Bestelmeyer et al. 2003).

$\mathrm{Al}$ analizar un conjunto ampliado de censos que abarcaron mejor el área geográfica de la Estepa Magallánica Seca encontramos limitaciones en el MEyT de Oliva y Borrelli (1993) (Figura 2) porque las comunidades clasificadas por el análisis de conglomerados (Figura 3) no se corresponden totalmente con los estados previamente descriptos. Apenas dos censos llegaron al límite inferior de cobertura de F. gracillima $(40-60 \%)$, que tiene el estado 1 del esquema anterior. Esto correspondería a unos pocos sitios en un estado prístino, como ya lo habían observado Roig et al. (1985), Anchorena (1985) y Borrelli et al. (1984). Estas comunidades podrían haber desaparecido del paisaje después de un siglo de pastoreo generalizado con altas cargas, pero es posible también que sean comunidades ideales que no han existido y que fueron planteadas en los modelos iniciales (Borrelli et al. 1988; Borrelli et al. 1984) porque requerían una comunidad de tipo climáxica. Por otro lado, en el modelo original se describen comunidades de P. chrysophylla, pero sólo asociadas a Estepas Subarbustivas de $N$. ulicina, y en este estudio identificamos invasiones de $P$. chrysophylla en diversas 
comunidades, incluyendo Coironales de alta cobertura y Estepas Subarbustivas. Estas diferencias entre el modelo y lo observado nos llevaron a plantear un nuevo modelo (Figura 4 y 5; Tabla 2).

El MEyT original (Figura 2) consideraba un eje principal dominado por la erosión y pérdida del horizonte superficial desde los Coironales hasta las Estepas Subarbustivas, mientras que el nuevo (Figura 4) incluye la pérdida de suelo en determinadas transiciones y la acumulación de sedimentos en otras. En el nuevo modelo se considera que el sobrepastoreo llevaría a una aceleración de la deflación y a una desorganización de los montículos asociados a los coirones que actúan como sumideros. La contraparte de este proceso sería que los sedimentos originados se depositarían alterando otras comunidades, un proceso a distintas escalas descripto como 'células de erosión' (Okin et al. 2006; Okin and Gillette 2001; Pickup 1985). La movilización de sedimentos cambiaría paulatinamente las condiciones edáficas de las áreas de pérdida y acumulación, y finalmente éstas se reflejarían en la composición botánica (Borrelli et al. 1984; Ellison 1949; Klemmedson 1956).

Roig y Faggi (1985) ya habían diferenciado comunidades vegetales asociadas a pérdida o acumulación de sedimentos. Las fisonomías subarbustivas serían consecuencia de la deflación acompañada por incremento de leñosas bajoaltas cargas de pastoreo, generando un mosaico de Estepas Subarbustivas de $N$. bryoides y pavimentos de erosión (i.e., parches de suelo desnudo con piedras en superficie expulsadas por el congelamientodescongelamiento). Al igual que estos autores, Borrelli et al. (1984) reconocieron que a medida que avanzaba la degradación del pastizal era más evidente la inestabilidad y el disturbio en el suelo: pavimentos de erosión, plantas en pedestal, suelo desnudo, pérdida de mantillo y disminución del espesor del horizonte superficial. Sin embargo, no describieron cambios en suelo producto de la acumulación de sedimentos que generan condiciones favorables para el establecimiento de $P$. chrysophylla, la especie del género que mejor se adapta a suelos muy sueltos, arenosos y más secos (Roig et al. 2003). Algunas formaciones de P. chrysophylla habían sido descriptas por Roig y Faggi (1985) como Islas de Stipa, pero para el 'Festucetum gracillimae', que son áreas pequeñas y dominadas exclusivamente por esta especie dentro de la matriz del coironal. En el presente trabajo observamos que extensas áreas de Coironales y Estepas Subarbustivas han sido invadidas por $P$. chrysophylla en coberturas variables (2-50\%) y se presentan dispersas dentro de una matriz de F. gracillima, N. bryoides o N. ulicina. Estas comunidades invadidas pueden ser amplias y se ubican mayormente hacia el norte, en coincidencia con las acumulaciones de arenas recientes que podrían ser resultado de un manejo inadecuado de los campos.

Trabajos anteriores (Borrelli et al. 1984; Faggi and Roig 1985; Oliva and Borrelli 1993) postularon que el deterioro de los pastizales del sur de Santa Cruz se manifestaría principalmente en la abundancia de leñosas, un rasgo común de la degradación de pastizales en Patagonia (Paruelo et al. 1993). En el nuevo MEyT, el deterioro podría conducir a leñosas o a invasiones de gramíneas adaptadas a los sustratos arenosos como $P$. chrysophylla, generando nuevos estados como el Coironal con P. chrysophylla y las Estepas Subarbustivas con P. chrysophylla.

En el nuevo catálogo se combinaron los estados que se diferenciaban en el trabajo de Oliva y Borrelli (1993) (Figura 2) por cobertura de pastos cortos: II y III, por un lado, y IV y $\mathrm{V}$, por otro. Los Pastos cortos son un grupo funcional dinámico que, a diferencia de los Coirones, se instalan fácilmente por semilla y crecen en cobertura bajo niveles de pastoreo moderado. Además, son palatables y, a pesar de que toleran el pastoreo, disminuyen a cargas elevadas y sostenidas; por esta razón, las transiciones que dependen de la cobertura de pastos cortos son reversibles y, de acuerdo con las propuestas por Bestelmeyer et al. (2003), serían fases dentro de un estado. Por lo tanto, el nuevo MEyT incluye sólo transiciones con cambios fisonómicos irreversibles en el suelo y la vegetación.

En el modelo propuesto las Estepas Subarbustivas de N. ulicina fueron agrupadas con las de $N$. bryoides en un mismo estado. Esto se debió a que, a pesar de que se amplió el número de relevamientos florísticos en la Estepa Magallánica Seca, el número de censos en los que $N$. ulicina resultó ser la especie dominante fue bajo y, en general, se encontraron en porciones reducidas del paisaje. En el análisis de conglomerados se agruparon los censos de $N$. ulicina junto con las Estepas de N. bryoides. Por otro lado, mientras que las Estepas de $N$. bryoides son características de lugares planos, zonales en la Estepa Magallánica Seca (Faggi and Roig 
1985; Roig and Faggi 1985), las dominadas por N. ulicina son claramente azonales, asociadas a áreas pequeñas y muy disturbadas en dormideros ovinos y laderas de orientación $\mathrm{N}$ que son difíciles de cartografiar a la escala del presente trabajo. Es necesario profundizar el estudio de estas dos comunidades que podrían diferenciarse en estados en el futuro y cartografiarse a una escala más detallada.

El análisis de los mapas obtenidos en este estudio indica una precisión total de $61 \%$ (Tabla 4). Este estudio compara la clasificación florística de las comunidades con su clase en el mapa y permite evaluar el margen de error de la cartografía, que se acentúa cuando se deben diferenciar clases fisonómicamente similares mediante información de sensores remotos. La mayor parte de los estados presentaron valores de precisión de uso cercanos o mayores a 70\% (Tabla 4), con lo cual se tiene una razonable seguridad de que lo que está marcado en el mapa corresponde efectivamente a ese estado en el campo. Una excepción es el caso de las Estepas Subarbustivas con P. chrysophylla (Sp), que tienden a confundirse con Coironales y Coironales Subarbustivos, probablemente porque la firma espectral de estas áreas con apenas $50 \%$ de cobertura sea variable por diferencias en la superficie del suelo, llevando a errores en la clasificación de la imagen.

La mayor parte de la superficie de la Estepa Magallánica Seca clasificó dentro de los Coironales (Figura 6 y Tabla 3). Estos pastizales están en buen estado de conservación y son dominantes hacia el sur del río Gallegos. Tienen porcentajes bajos de coirones amargos de $P$. chrysophylla $(<2 \%)$ y de subarbustos de $N$. bryoides $(<5 \%)$. Las precipitaciones en el sur son levemente superiores, en el rango de 200-260 $\mathrm{mm} / \mathrm{año}$, lo que favorece a F. gracillima, que generalmente ocupa suelos neutros o ácidos y bien drenados (Roig and Méndez 1993; Roig et al. 2003). Sin embargo, los contrastes de alambrados evidencian transiciones producto del manejo que ya habían sido identificadas con anterioridad. Existen unidades de manejo degradadas por completo a Estepas Subarbustivas (S) o a Estepas Subarbustivas invadidas por $P$. chrysophylla (Sp) producto de estas transiciones en el norte de la Estepa Magallánica Seca, posiblemente por el uso como invernada en grandes establecimientos que después fueron subdivididos.

La cartografía produce una instantánea del estado actual de la vegetación con independencia del proceso histórico, pero es posible identificar huellas de los efectos de más de un siglo de manejo ganadero de estos pastizales a través de contrastes de alambrado que evidencian transiciones pasadas. La Figura $7 b$ muestra la transición 1, que llevaría a un pasaje de Coironales (C) a Coironales Subarbustivos (Cs), probablemente por una reducción de F. gracillima asociada al pastoreo de altas cargas que desagregarían montículos que luego se erosionan. Los subarbustos se verían favorecidos en este proceso por una menor competencia por recursos y aumentarían su cobertura. La misma figura muestra que estos Coironales Subarbustivos (Cs) pueden pasar a Estepas Subarbustivas (S) a través de la transición 4, dado que el pastoreo intenso que reduciría la cobertura de gramíneas altas remanentes en los Coironales Subarbustivos y expondría la superficie del suelo, que se erosiona hasta exponer horizontes $\mathrm{B}_{t}$ o $\mathrm{B}_{w^{\prime}}$ un ambiente que se cubre de arbustos rastreros de Nardophyllum o $N$. ulicina. Estas dos transiciones son producidas por deflación y similares a las transiciones T5 y T9 planteadas en Borrelli y Oliva (2001). El proceso de acumulación de arenas no había sido descripto previamente, y da lugar a contrastes de alambrado que evidencian la transición 3, de Coironales Subarbustivos (Cs) a Coironales con $P$. chrysophylla (Cp) (Figura 7a), y la transición 5, de Estepas Subarbustivas (S) a Estepas Subarbustivas con P. chrysophylla (Sp) (Figura 7c). Estas últimas son comunidades graminosas, pero dominadas por el coirón amargo, y podrían perder las acumulaciones de arena para dar lugar a Estepas Subarbustivas con $P$. chrysophylla por la transición 6 (Figura 7a). Por último, la transición 7 podría haber generado el contraste entre las Estepas Subarbustivas con $P$. chrysophylla (Sp) a Coironales con $P$. chrysophylla (Cp) (Figura 7c) por acumulación adicional de arenas sobre las comunidades subarbustivas que carecen de F. gracillima; en este caso se generaría la variante de Cp dominada exclusivamente por el coirón amargo $P$. chrysophylla. Estas últimas dos transiciones muestran que los mantos de arena depositados serían dinámicos, y podrían variar en espesor, algo común en el avance de frentes medanosos.

A pesar de las evidencias de degradación pasada, en este trabajo se comprobaron cerca de 500000 ha de Coironales y 100000 ha de Coironales Subarbustivos en buen estado de conservación en la Estepa Magallánica que constituyen un recurso natural valioso desde el punto de vista de la hidrología, el control 
de la erosión y la provisión de hábitat para la biodiversidad local. La clave para mantener estos pastizales naturales en el futuro parece ser regular el efecto de la ganadería sobre las poblaciones de F. gracillima, que forman montículos que atrapan el suelo y recursos móviles (Schenkel, inédito), reteniendo los sedimentos que impulsan la invasión de $P$. chrysophylla, por un lado, y manteniendo por competencia una cobertura limitada de subarbustos, por otro lado. Estos Coironales abiertos permiten el desarrollo de comunidades más diversas de pastos cortos y hierbas (Oliva et al. 2016). Los coirones son gramíneas cespitosas que se reproducen principalmente por crecimiento vegetativo (Oliva et al. 2005, 2013) y, a pesar de no ser un forraje preferido por los ovinos, son sensibles al pastoreo (Faggi 1985). La carga ganadera del departamento Güer Aike, que incluye a la Estepa Magallánica Seca, llegó a un máximo en el censo ganadero de 1937 con 0.60 ovinos.ha ${ }^{1}$.año ${ }^{-1} \mathrm{y}$ se fue reduciendo de manera paulatina hasta 0.28 ovinos.ha ${ }^{-1}$.año ${ }^{-1}$ en 2017 (SENASA 2017). Modelos demográficos de poblaciones de coirones en el ensayo de pastoreo en la estancia Moy Aike demostraron que la mitad de las plantas se perdería en 37 años con cargas elevadas de 0.6 ovinos.ha ${ }^{-1} \cdot a_{n} o^{-1}$ (Oliva et al. 2005). A pesar de que todos los coeficientes de crecimiento poblacionales de F. gracillima fueron negativos en este estudio, las proyecciones demográficas sobre cargas ovinas moderadas de 0.20 ovinos.ha $^{-1} \mathrm{año}^{-1}$ (y no las clausuras totales) fueron las que estimaron una vida media más prolongada, de 87 años. Recientemente se compararon manejos ganaderos a escala productiva en Los Pozos, una estancia ubicada como Moy Aike, en un extremo árido del rango climático la Estepa Magallánica Seca, y se registró un crecimiento de $40 \%$ en la cobertura de coirones en 5 años bajo una presión de pastoreo continuo de carga flexible que se mantuvo por debajo de la capacidad de carga anual con un promedio de $0.27 \pm 0.03$ ovinos.ha $a^{-1} \cdot a n ̃ o o^{-1}$. Una carga ganadera similar, pero bajo un sistema holístico, con pulsos de pastoreo intensos y prolongados descansos, provoco una reducción no significativa del $6 \%$ de la cobertura de coirones (Oliva et al. 2021). Es probable que tanto la exclusión como los descansos prolongados favorezcan a pastos cortos, que son muy palatables para la hacienda, mientras que un régimen de pastoreo continuo de cargas moderadas reduzca la competencia de este grupo funcional sin afectar a los coirones.

Los diferentes estados de la Estepa Magallánica Seca son el resultado de la interacción del clima, el suelo y el manejo. El mapa y el Modelo de Estados y Transiciones que se presentan en este trabajo permiten interpretar mejor la dinámica de una de las áreas ecológicas más diversas y productivas de Patagonia. También permite observar que el manejo puede ocasionar transiciones irreversibles que derivan en estados muy pobres en cuanto a cobertura y diversidad (Oliva et al. 2016). Una parte de estos pastizales probablemente debería ser protegida en el futuro, ya que prácticamente no existen áreas de conservación para la región. Toda la superficie remanente de la Estepa Magallánica Seca debería ser conservada en forma activa en los establecimientos ganaderos por medio de un manejo con cargas moderadas y descansos administrados que aseguren el mantenimiento de la biodiversidad, la productividad y los servicios ecosistémicos de estos pastizales únicos.

Agradecimientos. A María Eugenia Vivar, Juan Carlos Kofalt y Carla Cepeda del grupo de RRNN de la EEA Santa Cruz INTA que participaron en relevamientos de vegetación. Este trabajo se realizó en el marco de un plan de tesis de Doctorado en la FAUBA, mediante una beca doctoral INTA. Agradezco a mi codirector, Mario Rostagno y a mi director de beca INTA Guillermo Clifton.

\section{ReFERENCIAS}

Anchorena, J. 1978. Regiones Ecológicas de la Patagonia. Primer curso de Manejo de Pastizales. INTA: Bariloche, Rio Negro. Pp. 8.

Anchorena, J. 1985. Recursos naturales y aptitud de uso ganadero. Dos cartas a escala 1:40.000 para la región magallánica. In O. Boelcke, D. Moore and F. Roig (eds.). Transecta Botánica de la Patagonia Austral. Buenos Aires: CONICET, Instituto de la Patagonia y Royal Society.

Barbería, E. 1995. Los dueños de la tierra en la Patagonia Austral. Buenos Aires: Universidad Federal de la Patagonia Austral. Pp. 475.

Bestelmeyer, B. T., J. Brown, K. M. Havstad, R. Alexander, G. Chaverz, and J. E. Herrick. 2003. Development and Use of State-and-Transition Models for Rangelands. Journal of Range Management 56:114-126. https://doi.org/10.2307/ 4003894.

Borrelli, P., F. Anglesio, C. Baetti, M. Iacomini, and A. Ramstrom. 1988. Condición de pastizales en el sudeste de Santa 
Cruz (Patagonia) II: Sitio “Santacrucense”. Revista Argentina de Producción Animal 8(3):201-213.

Borrelli, P., C. Cheppi, M. Iacomini, and A. Ramstrom. 1984. Condición de pastizales en el sitio terraza de Río Gallegos. Revista Argentina de Producción Animal 4(9):879-897.

Borrelli, P., M. Iacomini, C. Baetti, and F. Anglesio. 1987. Áreas ecológicas de Santa Cruz y norte de Tierra del Fuego.

Borrelli, P., and G. Oliva. 2001. Efectos de los animales sobre los pastizales. Pp. 99-128 in P. Borrelli and G. Oliva (eds.). Ganadería sustentable en la Patagonia austral. Buenos Aires: INTA Reg Patagonia Sur and GTZ.

Bran, D., G. Oliva, P. Rial, J. Escobar, C. López, F. Umaña, J. Ayesa, and N. Elissalde. 2005. Regiones Ecológicas Homogéneas de la Patagonia Argentina. Bariloche: INTA. Pp. 12.

Braun Blanquet, J. J. 1932. Plant sociology, the study of plant communities. New York: Hafner Pub Co. Pp. 439.

Burgos, J. 1985. Clima en el extremo sur de Sudamérica. Pp. 10-40 in O. Boelcke, D. Moore and F. Roig (eds.). Transecta botánica de la Patagonia Austral. Buenos Aires: CONICET, Instituto de la Patagonia y Royal Society.

Cabrera, A. 1971. Fitogeografia de la República Argentina. Boletín de la Sociedad Argentina de Botánica 14:1-42.

Cook, C. W., and L. Kothmann. 1965. Effect of Range Condition and Utilization on Nutritive Intake of Sheep on Summer Ranges. Rangeland Ecology and Management / Journal of Range Management Archives 18:69-73. https: //doi.org/10.2307/3895470.

De Fina, A., A. Garbosky, F. Gianetto, and L. Sabella. 1968. Difusión geográfica de cultivos índices en la Provincia de Santa Cruz. Buenos Aires: INTA. Pp. 30.

Di Rienzo, J., F. Casanoves, M. Balzarini, L. González, M. Tablada, and C. Robledo. 2011. InfoStat versión 2011. Grupo InfoStat, FCA, Universidad Nacional de Córdoba, Argentina. URL: infostat.com.ar.

Dyksterhuis, E. J. 1958. Ecological principles in range evaluation. Botanical Review 24:253-272. https://doi.org/10.1007/ BF02872569.

Ellison, L. 1949. The ecological basis for judging condition and trend on mountain range land. Journal of Forestry 47: 786-795.

Faggi, A. 1983. Cartas de la vegetación real y potencial de la Ea. Cabo Buen Tiempo. Parodiana 3:341-364.

Faggi, A. 1985. Las comunidades vegetales de Rio Gallegos, Santa Cruz. Pp. 592-633 in O. Boelcke, D. Moore and F. Roig (eds.). Transecta Botánica de la Patagonia Austral. Buenos Aires: CONICET Instituto de la Patagonia (Chile) Royal Society (Gran Bretaña).

Faggi, A., and F. Roig. 1985. Carta fitosociológica de Río Gallegos. Provincia de Santa Cruz, República Argentina. In O. Boelcke, D. Moore and F. Roig (eds.). Transecta Botánica de la Patagonia Austral. Buenos Aires: CONICET,Instituto de la Patagonia y Royal Society.

Ferrante, D., G. Oliva, G. Humano, and P. Torra. 2004. Dinámica del agua en una estepa graminosa de la Patagonia Austral. Actas II Reunión Binacional de Ecologia. Pp 302. 31 de octubre al 5 de noviembre, Mendoza.

Friedel, M. 1991. Range condition assessment and the concept of thresholds: a viewpoint. Journal of Range Management 44:422-426. https://doi.org/10.2307/4002737.

Hongslo, E. 2015. An ecology of difference: fence-line contrast photographs as scientific models in ecology. Journal of Political Ecology 22:349-356. https://doi.org/10.2458/v22i1.21112.

Klemmedson, J. O. 1956. Interrelations of vegetation, soils and range conditions induced by grazing. Journal of Range Management 9:134-138. https://doi.org/10.2307/3894234.

Laycock, W. 1991. Stable states and thresholds of range condition on North American rangelands: A viewpoint. Journal of Range Management 44:427-433. https://doi.org/10.2307/4002738.

León, R., D. Bran, M. Collantes, J. Paruelo, and A. Soriano. 1998. Grandes unidades de vegetación de la Patagonia extra andina. Ecología Austral 8:125-144.

Mazzoni, E. 2001. Distribución espacial y caracterización geomorfológica de "Bajos sin Salida" de la Patagonia Austral Extracordillerana. Anales Instituto Patagonia. Serie Ciencias Naturales (Chile) 29:5-24.

Okin, G., D. Gillette, and J. Herrick. 2006. Multi-scale controls on and consequences of aeolian processes in landscape change in arid and semi-arid environments. Journal of Arid Environments 65:253-275. https://doi.org/10.1016/ j.jaridenv.2005.06.029.

Okin, G. S., and D. A. Gillette. 2001. Distribution of vegetation in wind-dominated landscapes: Implications for wind erosion modeling and landscape processes. Journal of Geophysical Research: Atmospheres 106:9673-9683. https: //doi.org/10.1029/2001JD900052.

Oliva, G., and P. Borrelli. 1993. Estepas del sudeste de Santa Cruz. Pp. 5-13 in J. Paruelo, M. Bertiller, T. Schlichter and F. Coronato (eds.). Secuencias de deterioro en distintos ambientes patagónicos: Su caracterización mediante el modelo de Estados y Transiciones. Bariloche: Ludepa SME.

Oliva, G., D. Bran, J. Gaitán, D. Ferrante, V. Massara, G. G. Martínez, E. Adema, M. Enrique, E. Domínguez, and P. Paredes. 2019. Monitoring drylands: The MARAS system. Journal of Arid Environments 161:55-63. https://doi.org/ 10.1016/j.jaridenv.2018.10.004.

Oliva, G., A. Cibils, P. Borrelli, and G. Humano. 1998. Stable states in relation to grazing in Patagonia: A 10-year experimental trial. Journal of Arid Environments 40:113-131. https://doi.org/10.1006/jare.1998.0425.

Oliva, G., M. Collantes, and G. Humano. 2005. Demography of Grazed Tussock Populations in Patagonia. Rangeland Ecology and Management 58:466-473. https://doi.org/10.2111/1551-5028(2005)58[466:DOGTGP]2.0.CO;2.

Oliva, G., M. Collantes, and G. Humano. 2013. Reproductive Effort and Seed Establishment in Grazed Tussock Grass Populations of Patagonia. Rangeland Ecology and Management 66:164-173. https://doi.org/10.2111/REM-D-1100121.1. 
Oliva, G., D. Ferrante, C. Cepeda, G. Humano, and S. Puig. 2021. Holistic versus continuous grazing in Patagonia: A station-scale case study of plant and animal production. Rangeland Ecology and Management 74:63-71. https: //doi.org/10.1016/j.rama.2020.09.006.

Oliva, G., D. Ferrante, P. Paredes, G. Humano, and A. Cesa. 2016. A conceptual model for changes in floristic diversity under grazing in semi-arid Patagonia using the State and Transition framework. Journal of Arid Environments 127: 120-127. https://doi.org/10.1016/j.jaridenv.2015.10.018.

Oliva, G., L. González, P. Rial, and E. Livraghi. 2001. El ambiente en la Patagonia Austral. Pp. 17-80 in P. Borrelli and G. Oliva (eds.). Ganadería ovina sustentable en la Patagonia Austral. Cap. 2. Buenos Aires: INTA EEA Santa Cruz.

Paruelo, J. M., M. B. Bertiller, T. M. Schlichter, and F. R. Coronato. 1993. Secuencias de deterioro en distintos ambientes patagónicos. Su caracterización mediante el modelo de estados y transiciones. Bariloche: LUDEPA. Convenio INTAGTZ. Pp. 109.

Pickup, G. 1985. The erosion cell - a geomorphic approach to landscape classification in range assessment. Australian Rangeland Journal 7:114-121. https://doi.org/10.1071/RJ9850114.

Ramos, V. A. 1999. Las provincias geológicas del territorio argentino. Geología Argentina 29:41-96.

Roig, F., J. Anchorena, A. Dollenz, A. Faggi, and E. Méndez. 1985. Las comunidades vegetales de la transecta botánica de la Patagonia Austral. Primera parte. La vegetación del área continental. Pp. 350-456 en O. Boelcke, D. Moore and F. Roig (eds.). Transecta Botánica de la Patagonia Austral. Buenos Aires: Conicet- Royal Society- Instituto de la Patagonia.

Roig, F., and A. Faggi. 1985. Transecta Botánica de la Patagonia Austral: Análisis geobotánico de la vegetación. Buenos Aires: CONICET. Pp. 189.

Roig, F., and E. Mendez. 1993. Estepas magallánicas de Festuca gracillima de Santa Cruz. Pp. 5-13 in J. Paruelo, M. Bertiller, T. Schlichter and F. Coronato (eds.). Secuencias de deterioro en distintos ambientes patagónicos: Su caracterización mediante el modelo de Estados y Transiciones. Bariloche: Ludepa SME.

Roig, F., E. Méndez, E. Abraham, D. Tomasini, and P. Mascagno. 2003. Especies indicadoras de estados y procesos en la vegetación patagónica. Indicadores y Puntos de Referencia en América Latina y el Caribe. Pp. 189-208.

SENASA. 2017. Existencias ovinas por categoria y departamento 2008-2017. URL: tinyurl.com/wava6u6j.

Soriano, A., M. Nogués Loza, and S. Burkart. 1995. Biodiversity in the extra-Andean Patagonia: Comparison with neighboring and related vegetation units. En L. Montes and G. Oliva (eds.). Actas del Taller Internacional sobre recursos fitogenéticos desertificación y uso sustentable. Buenos Aires: Centro Regional Patagonia Sur INTA. Pp. 238.

Story, M., and R. G. Congalton. 1986. Accuracy assessment: a user's perspective. Photogrammetric Engineering and remote sensing 52:397-399.

Westoby, M., B. Walker, and I. Noy-Meir. 1989. Opportunistic management of rangelands not at equilibrium. Journal of Range Management 42:266-274. https://doi.org/10.2307/3899492.

Zuloaga, F., O. Morrone, and M. Belgrano. 2009. Catálogo de las Plantas Vasculares del Cono Sur. Versión base de datos en sitio web. Instituto Darwinion. 